\title{
Early maturing Kipsigis women have higher reproductive success than late maturing women and cost more to marry
}

\author{
Monique Borgerhoff Mulder \\ Evolution and Human Behavior Program, Rackham Building, University of Michigan, Ann Arbor, MI 48109-1070, USA
}

Received February 1, 1988 / Accepted October 4, 1988

Summary. Demographic analyses from 3 cohorts of Kenyan Kipsigis women married between 1940 and 1973 demonstrate that early maturing women have higher reproductive success than do late maturing women, due to longer reproductive lifespans and higher fertility. This result is independent of confounding effects of husband's wealth, but not of the wealth of a woman's parents which affects both menarcheal age and subsequent reproductive success. Data on bridewealth payments at 194 marriages occurring after 1959 show that men make higher marriage payments for early maturing women than for late maturing women. Together these results suggest that Kipsigis men vary their marriage payments in accordance with the reproductive value of their brides. The question of why men use age at menarche rather than bride's parents' wealth as a cue to their bride's subsequent reproductive performance is discussed in the light of changing social and economic conditions experienced by Kipsigis since the late 1920s.

\section{Introduction}

Humans mate selectively, but both the criteria on which marriage partners are chosen and the reproductive effects of such selectivity remain unclear (Thiessen and Gregg 1980; Epstein and Guttman 1985). To identify the adaptive significance of mate choice, the criteria by which partners are chosen and the factors responsible for fertility differences between couples must be determined (Mascie-Taylor 1988). Societies in which men purchase their brides through negotiated marriage payments offer a unique opportunity to examine both the characteristics of women that are favored by men as well as the reproductive correlates of such traits. While it is hardly a foregone conclusion among anthro- pologists that human mate choice is adaptive, the analyses presented here provide some support for such an assumption. More interestingly, they indicate that intercultural variability in marriage payments can be fruitfully examined from the perspective of behavioral ecology.

In the Kipsigis people of Kenya, as in many traditional populations (e.g. Mair 1969; Comaroff 1980), men must pay for their wives. The size of this "bridewealth" payment is agreed on after protracted negotiations between the families of the bride and the groom. Given that average bridewealth approximates one third of the value of an average man's wealth, it can be considered as representing a significant proportion of a man's mating effort. Study of the variability in bridewealth payments in relation to the determinants of reproductive success of Kipsigis women thus provides a clear test of whether men in this population expend resources in aquiring mates on the basis of reproductive value (Fisher 1958).

Kipsigis are a Nilotic Kalenjin-speaking people of Rift Valley Province, Kenya. Traditionally they were almost exclusively pastoralist, hearding cattle, goats and sheep on communally-held land (Peristiany 1939). With the introduction of maize in the late 1920 s, they rapidly shifted to an agro-pastoral economy (Peristiany 1939; Manners 1967), leading to the development of individual rights to land among men (Saltman 1977).

Kipsigis practise patrilineal inheritance and prefer to marry polygynously. Livestock and land are owned exclusively by men and passed to each of a man's wives' sons at (or a little before) his death. Homesteads lie at approximately 200 300 metres from one another; they are composed of the households of related men (usually a man, his married sons and perhaps one or more married brothers), the wives of these men, and their unmarried children. 
Each year in early December a clitoridectomy ("circumcision") operation is held in the community. All women undergo this operation immediately on reaching menarche (between 12 and 20 years in this population), after which they spend several months in seclusion prior to marriage. At marriage the groom's father makes a bridewealth payment of cows, goats and (since 1960) Kenyan shillings to the bride's father (Borgerhoff Mulder 1988a); payments for subsequent marriages are made by the groom rather than his father. After marriage the bride moves from her natal home to that of her husband; she obtains her entire subsistence from his land and cattle, and bears his children (Borgerhoff Mulder 1987a); divorce is almost unknown (Peristiany 1939; Orchardson 1961).

\section{Methods}

\section{Demographic data collection}

A Kipsigis population, little affected by the rapid modernization transforming much of rural Kenya, was studied on the borders of Kericho and Narok Districts between June 1982 and December 1983 (Borgerhoff Mulder 1985). The terrain in this area is varied and hilly, including poorly drained heavy loam soils with scrubby vegetation, easily cultivable gentle sloping hillsides and stony thicketted ridges (Pilgrim 1961), receiving approximately 40 inches of rain per annum.

I interviewed in Kipsigis language all women of reproductive age in the study area ( $35 \mathrm{sq} . \mathrm{kms})$ and determined dates of birth, clitoridectomy, marriage, number and age of surviving offspring and (where possible) number of live-births. Life history events were dated to the year through the use of a calendar of local events such as notable ceremonies, severe droughts, eclipses, the sight of the first jet airplane and administrative changes. Eighteen months residence in the area and use of the indigenous language permitted various reliability checks for the validity of reported demographic data to be conducted (see Borgerhoff Mulder 1987b).

Women were divided into cohorts according to the year of their marriage. Three cohorts of women are analyzed in this paper: Chuma (married 1940-1953), for whom data on completed lifetime reproductive success are now available (Borgerhoff Mulder 1988 b), cohort I (married 1954-1963) and cohort II (1964-1973) for whom 20-30 and 10-20 married reproductive years can be sampled respectively; for further details of the sample see Borgerhoff Mulder (1987a).

\section{Age at menarche}

Age at clitoridectomy was used as a measure of differences in age at menarche because of the Kipsigis' custom of sending girls for this operation the December following first menses. Estimating menarcheal age in this way raises some problems. First, there are inevitably cases where the custom is not followed; for example, two closely-spaced daughters may (I saw one instance) be sent for clitoridectomy only when the younger reaches menarche, thus delaying the operation for the elder. Second, even when the custom is followed, the estimation procedures used in this paper result in the casting of women who may have been only a few weeks apart in age at first menses (specifically in late November and early December) into differ- ent clitoridectomy age groups (and of women who were 11 months apart into the same clitoridectomy age group). Because of the 1 year error in estimating menarcheal age from age at clitoridectomy in this way, any dictotomous ranking of women according to age at menarche must drop the median category for statistical procedures to be valid. Consequently, statistical tests (Student's $t$ ) were conducted on comparison between women who underwent clitoridectomy aged 12-14 and those aged 16-19, subsequently termed early and late maturers. These categories will include a few incorrectly ranked individuals for whom the usual customs were not followed, constituting unsystematic bias in both samples. Data for the full range of clitoridectomy ages are presented only in the Figs. 1, 3 and 4 and are tested with Pearsons correlations coefficients.

\section{Reproductive measures}

Women's reproductive success was broken down into 3 components: length of married lifespan $\left(\mathrm{L}_{\mathrm{x}}\right)$, calculated as date of last live-birth minus date of marriage; fertility (F), calculated as the number of live-births divided by length of reproductive lifespan; and offspring survival (S), calculated as the total number of offspring surviving to 21 years (or to the present if born after 1963) divided by the number of live-births. Reproductive success was measured as the number of surviving offspring for Chuma women (who have terminated childbearing) and the number of surviving offspring per married year for cohort I and II women.

\section{Samples}

In the Chuma, I and II cohorts there were 33, 83 and 201 women respectively whose age at clitoridectomy was known (Chuma $\bar{x}=15.4$ years, SD 1.9, range $12-19$; cohort $\mathrm{I} \bar{x}=15.1, \mathrm{SD}=1.6$, range 12-18; cohort II $\bar{x}=15.0, \mathrm{SD}=1.5$, range $12-20$ ). Sample sizes (in the statistical tests to follow) vary due to dropping girls who underwent clitoridectomy at 15 years (see above) and cases with inadequate information on various components of reproductive success or socioeconomic measures (see below).

\section{Socioeconomic measures}

Husband's land ownership (Borgerhoff Mulder 1987b), parental land ownership (Borgerhoff Mulder 1989a), husband's age, widowed status, wife's education and distance between natal and marital households were recorded for all possible households in the study area (for full details Borgerhoff Mulder $1987 \mathrm{c})$. In examining the effects of parental wealth on women's reproductive success, analyses were restricted to data from cohort II, a cohort for which estimations of parental wealth were available and an adequate number of reproductive years $(10-20)$ sampled $(n=44)$. Women whose parents had been resettled at Kenyan Independence (1963) were excuded from these analyses because the present size of their parents' farm may bear little relation to that used before 1960 , on which they were raised.

\section{Bridewealth}

Bridewealth payments were documented through interviews with all household heads in an intensively studied community within the study site (Borgerhoff Mulder 1988a). Reliable information on bridewealth payments was only available for marriages occurring after $1959(n=194)$. Excluding cases where the bride was either pregnant or no longer nulliparous at marriage ( $6 \%$ of all marriages) payments for 161 brides of known age at clitoridectomy were recorded. For comparative purposes, 
payments were converted into units equivalent to the monetary value of a cow at the time of the marriage. Reliability of reports were tested by comparing the responses of donor and recipient families (see Borgerhoff Mulder 1988a). Because inaccuracies inevitably arise in assessing past monetary value of livestock from local market records, bridewealth payments were categorized according to whether they fell in the upper, middle or lower percentile range and tested with non-parametric statistics (G-tests).

\section{Results}

\section{Age at menarche and reproductive success}

Early maturing women had higher reproductive success than late maturing women in all 3 cohorts for which age at menarche could be determined (see Table 1; data for Chuma women of all clitoridectomy ages are shown in Fig. 1). Using an ANOVA model that controls for the effects of all variables simultaneously (SPSSx Users' Guide 1983), the effects of age at menarche were shown to be independent of other significant factors affecting reproductive success (cf. Borgerhoff Mulder 1987a, 1987c): husband's wealth in the Chuma cohort $\left(f_{1,30}=9.18, P<0.01\right)$, husband's wealth, his youth and his survivorship in cohort I $\left(f_{1,77}=\right.$ $12.05, P<0.001)$ and woman's education in cohort II $\left(f_{1,198}=5.21, P<0.05\right)$.

Age specific production of surviving offspring born to early and late maturing Chuma women (Fig. 2) shows that high reproductive performance of early maturers is experienced at all stages of the reproductive lifespan, though most strongly in the earlier years.

Turning to the components of reproductive success, differences between early and late maturers in the length of reproductive lifespan $\left(\mathrm{L}_{\mathrm{r}}\right)$, production of live-births per year (F), and proportion of offspring that survive (S) are shown in Table 2 .

Women who reach menarche early experienced longer reproductive lifespans ( $X=24.5$ years) than did those who reached menarche late (20.3 years). Data for Chuma women of all clitoridectomy ages are shown in Fig. 3; in currently reproductive cohorts this relationship could not, of course, be examined. Early maturers experienced younger ages at first birth ( $X=17.3$ years) than did late maturers (19.9 years, $t_{12,14}=-4.95, P<0.001$ ) although the interval between marriage and first birth was longer $\left(X=1.3\right.$ as opposed to 1 year, $t_{12,14}=2.34, P<$ $0.05)$. Age at last birth did not differ between early $(X=39.3$ years) and late maturers (38.5 years, $t_{12,14}=0.47$, NS, details in Borgerhoff Mulder 1989 b).

In all 3 cohorts early maturing women had
Table 1. Age at menarche and reproductive success of women ${ }^{\text {a }}$ (mean values with $t$-test)

\begin{tabular}{lll}
\hline Cohort & \multicolumn{2}{l}{ Reproductive success } \\
\cline { 2 - 3 } & $12-14$ & $16-19$ \\
\hline Chuma (1940-53) & 8.58 & 5.79 \\
& $t_{12,14}=3.33^{* *}$ & \\
Cohort I (1954-63) & 0.33 & 0.26 \\
& $t_{30,27}=3.09^{* *}$ & \\
Cohort II (1964-73) & 0.39 & 0.34 \\
& $t_{70,61}=2.33^{*}$ & \\
\hline
\end{tabular}

a Reproductive success is measured as lifetime reproductive success for Chuma cohort, and as number of surviving offspring per year for cohorts I and II;

$* P<0.05$, all probabilities are two-tailed; ${ }^{*} P<0.01$

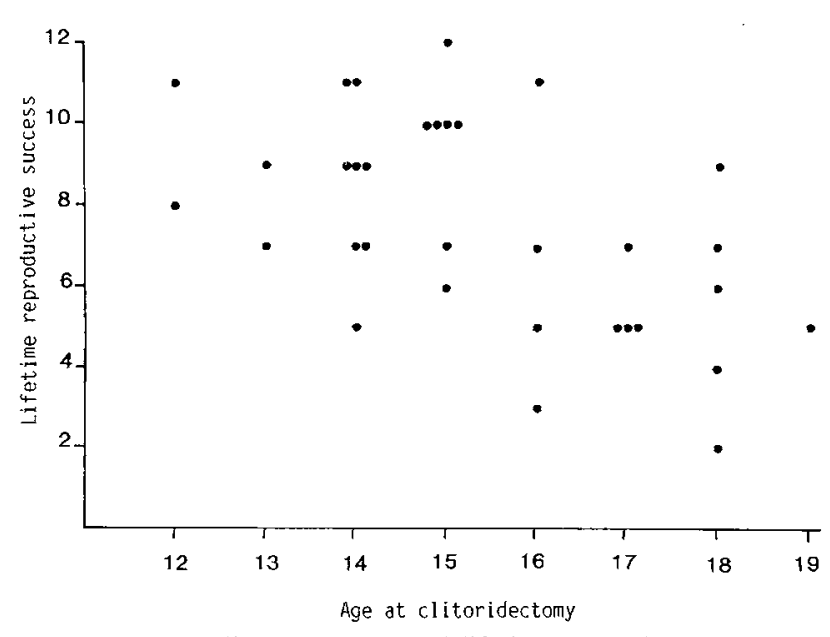

Fig. 1. Age at clitoridectomy and lifetime reproductive success for 33 women in the Chuma cohort (Pearson $r=-0.53, P<$ 0.001 , two-tailed)

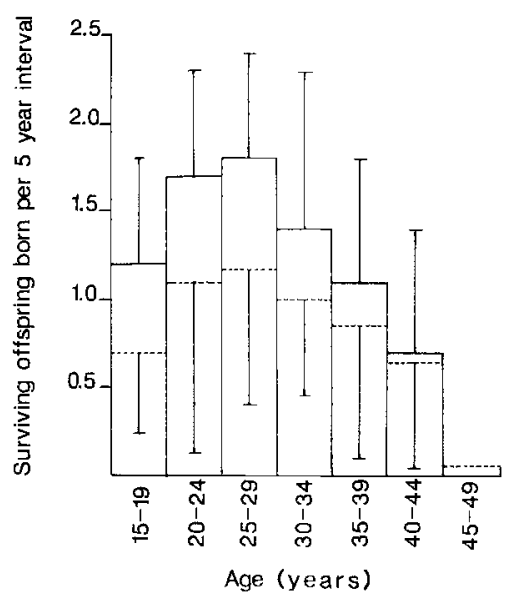

Fig. 2. Age-specific production of surviving offspring born to early $(n=9)$ and late $(n=13)$ maturing women in the Chuma cohort. Clear bars (with ascending standard deviations) represent early maturing women, dashed bars (with descending standard deviations) represent late maturing women 
Table 2. Age at menarche and the components of reproductive success in women (mean values with $t$-test)

\begin{tabular}{|c|c|c|c|c|c|c|}
\hline \multirow[t]{2}{*}{ Cohort } & \multicolumn{2}{|c|}{$\begin{array}{l}\text { Reproductive lifespan (years) } \\
\left(L_{r}\right)\end{array}$} & \multicolumn{2}{|c|}{$\begin{array}{l}\text { Live-births per year } \\
\text { (F) }\end{array}$} & \multicolumn{2}{|c|}{$\begin{array}{l}\text { Probability offspring survive } \\
\text { (S) }\end{array}$} \\
\hline & $12-14$ & $16-19$ & $12-14$ & $16-19$ & $12-14$ & $16-19$ \\
\hline \multirow[t]{2}{*}{ Chuma (1940-53) } & 24.5 & 20.3 & 0.40 & 0.36 & 0.89 & 0.83 \\
\hline & \multicolumn{2}{|c|}{$t_{12,14}=2.23^{*}$} & \multicolumn{2}{|c|}{$t_{12,14}=1.00$} & \multicolumn{2}{|c|}{$t_{12,14}=1.32$} \\
\hline \multirow[t]{2}{*}{ Cohort I (1954-63) } & - & & 0.38 & 0.33 & 0.88 & 0.83 \\
\hline & & & \multicolumn{2}{|c|}{$t_{30.26}=2.11^{*}$} & \multicolumn{2}{|c|}{$t_{30,26}=1.09$} \\
\hline \multirow[t]{2}{*}{ Cohort II (1964-73) } & - & & 0.43 & 0.40 & 0.90 & 0.86 \\
\hline & & & \multicolumn{2}{|c|}{$t_{69,56}=2.00^{*}$} & \multicolumn{2}{|c|}{$t_{69,56}=1.33$} \\
\hline
\end{tabular}

$* P<0.05$

more live-births per year $(\mathrm{F})$ than did late maturing women, although the difference was only significant in two cohorts (Table 2; see Fig. 4 for data on cohort I women of all clitoridectomy ages). In cohort I fertility was positively affected by husband's wealth and his youth (Borgerhoff Mulder 1987a, 1987c), but the effects of age at menarche were still significant after these variables had been controlled $\left(f_{1,70}=5.79, P<0.05\right)$, using the same ANOVA model as above.

Although early maturing women had consistently higher offspring survival than did late maturing women (Table 2), in no cohort was the difference significant.

\section{Parental wealth influences on age at menarche}

The wealth of a woman's parents was negatively associated with her age at menarche (Pearson $r=$ $-0.35, n=38, P<0.05$, two-tailed) and positively associated with reproductive success $(r=0.41, n=$ $44, P<0.01$, two-tailed). Parental wealth was associated (weakly) with improved offspring survival $(r=0.28, n=44,0.05>P<0.10)$ rather than fertility $(r=0.20, n=44$, NS). The relative importance of parental wealth and menarcheal age on reproductive success was tested using analysis of variance, alternatively forcing the entry of the factor (age at menarche $<15$ or $>15$ years) and the covariate (parental wealth). When age at menarche was entered first $\left(f_{1,24}=8.07, P<0.01\right)$, parental wealth explained a further significant proportion of the variance $\left(f_{1,23}=4.40, P<0.05\right)$. In the second analysis, when parental wealth was entered first $\left(f_{1,24}=11.20, P<0.01\right)$, age at menarche failed to explain further variance $\left(f_{1,23}=1.27, \mathrm{NS}\right)$. In short, a woman's parents' wealth affects her reproductive success even after age at menarche is controlled whereas the converse is not true. Parental wealth is a stronger predictor of reproductive success than is age at menarche.

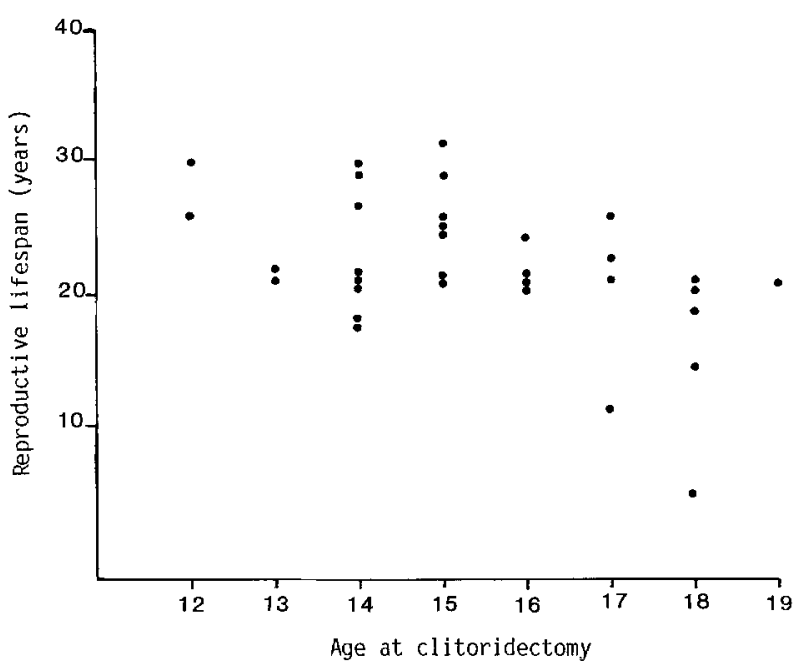

Fig. 3. Age at clitoridectomy and length of reproductive lifespan for 33 women in the Chuma cohort (Pearson $r=-0.48, P<$ 0.01 , two-tailed)

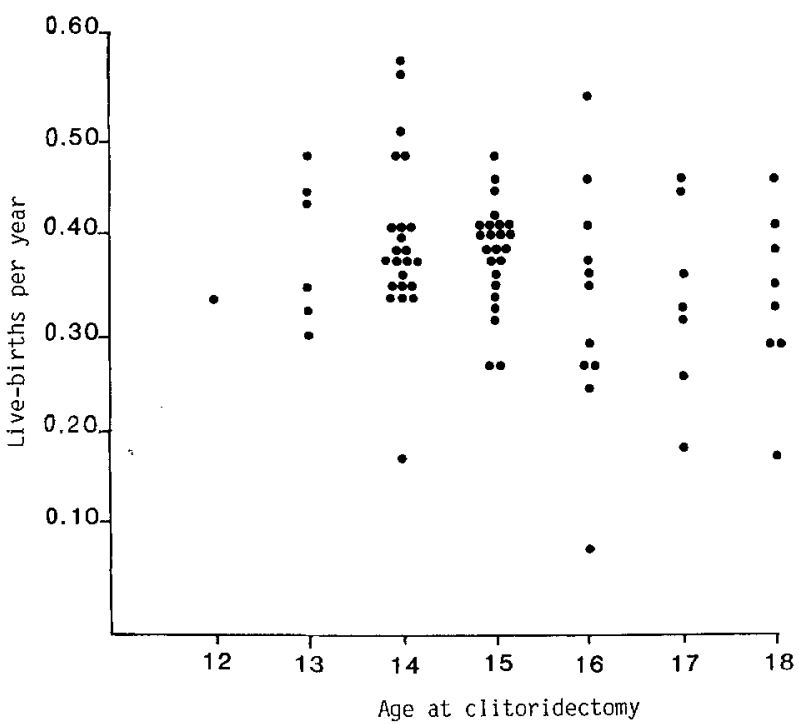

Fig. 4. Age at clitoridectomy and number of live-births per married year for 80 women in cohort I (Pearson $r=-0.22, P<$ 0.05 , two-tailed) 




Age at menarche

Fig. 5. The number of bridewealth payments $(n=130)$ categorized as high, average or low (see text) for women reaching menarche in the earlier (E) and late (L) categories

\section{Bridewealth payments}

High bridewealth payments (falling in the upper third of the distribution) were more frequently paid for early maturing women than for late maturing women, with payments varying systematically according to age at menarche $(G=12.37, d f=2, n=$ 130, $P<0.01$, see Fig. 5); this result could not be attributed to the general increase in bridwealth payments over time (Borgerhoff Mulder 1988a). Other factors affecting bridewealth values have been presented in detail elsewhere (Borgerhoff Mulder 1988a); they can be summarized through examining the $G$-test 3 way interaction terms (3-way $G$ ) between bridewealth, age at menarche and the potentially confounding factor.

The association between bridewealth units and age at menarche was independent of educational experience of the bride ( 3 or more years) (3-way $G=0.44, d f=2, n=129$, NS), whether the bride is a man's first or subsequent wife (3-way $G=0.24$, $d f=2, n=130, \mathrm{NS})$ and the distance between natal and marital homes $(<2 \mathrm{kms},=>2 \mathrm{kms}$ ) (3-way $G=2.88, d f=2, n=130$, NS). Neither the wealth of the bride's father nor the wealth of the groom's father (above or below the median of the sample) was systematically associated with high, average or low bridewealth payments $(G=2.08, d f=2, n=$ $130, \mathrm{NS} ; G=2.14, d f=2, n=108$, NS respectively); furthermore, there was no significant interaction between bride's parents' wealth, age at menarche and bridewealth (3-way $G=2.62, d f=2, n=98$, NS) nor between groom's parents' wealth, bride's menarcheal age and bridewealth (3-way $G=0.75$, $d f=2, n=81$, NS). In short, these results show that early maturing brides cost more than late maturing brides, and that this association is independent of educational differences among brides, marital status, distance between the natal and marital home, and the wealth of the bride's and groom's parents.

Finally, given the importance of parental wealth in determining a woman's reproductive success in cohort II, I looked to see if parental wealth has recently become an important determinant of bridewealth, by splitting marriages according to whether they occurred betwen 1960-71 or 1972-83. Bride's parents' wealth showed no positive affects of bridewealth in either the earlier or the later period, nor was there any significant interaction (3-way $G=1.61, d f=2, n=130$, NS).

\section{Discussion}

Are Kipsigis men behaving adaptively (c.f. Borgerhoff Mulder 1987d) in paying higher bridewealth for early than late maturing women? While bridewealth amounts cannot be directly related to differences in reproductive success (reported bridewealth values are unreliable prior to 1960), the demographic findings reported here suggest that Kipsigis men have, at least since 1960 , paid more for wives of high reproductive value (Fisher 1958), who are likely to leave above average numbers of descendents. This is consistent with the prediction (Williams 1975) that males should be more attracted to females of high reproductive value than to women with high current reproductive capacity.

In this discussion, I examine two questions. First, what factors may underlie the high reproductive success of early maturing Kipsigis women? Second, why do men not pay inflated bridewealth for brides with rich parents, given that parental wealth is such an important determinant of a woman's reproductive success? This latter question raises the more speculative yet, I believe, critical issue of whether "rules of thumb" guiding adaptive behavioral responses become outmoded in rapidly changing environments (c.f. Caro and Borgerhoff Mulder 1987).

\section{Age at menarche and reproductive success}

Negative associations between age at menarche and certain aspects of reproductive performance have been shown in a number of studies. Late maturing women in the USA have longer birth intervals and are less fertile at older ages and higher parities than early maturers (Ryder and Westoff 1971), they are more likely to be infertile (Cutler et al. 1979) and, at least in older cohorts, have fewer live-births (Sandler et al. 1984). Among Romanian women, late puberty is associated with low total fertility (Critescu 1975). Malaysian women 
reaching menarche before 15 years of age are more likely to give birth within the first 12 months of marriage than are women maturing at 15 or older (Udry and Cliquet 1982). Rather more indirect evidence for the negative association between age at menarche and reproductive performance comes from studies focusing on the reproductive correlates of a woman's age at marriage or first birth: thus women who marry young have more livebirths in Nepal (Gubhaju 1983) and larger completed family sizes in the USA (Bumpass et al. 1978), and age at first birth and completed family size are negatively correlated in western Malaysia (Aghajanian 1981).

At least three explanations can be offered for the differences in reproductive performance between early and late maturing women: (a) the earlier a woman starts childbearing, the more available time remains for her to continue childbearing; (b) the later a woman starts reproducing, the more likely she is to have entertained other ambitions than motherhood, for example employment; (c) underlying physiological differences between early and late maturers may account for subsequent differences in the timing of reproductive events and in overall reproductive performance. Each of these explanations is considered in the light of the Kipsigis findings.

a) Length of reproductive lifespan. Early maturing women should enjoy longer reproductive careers than late maturers, although only if age at menopause is relatively invariate with respect to menarcheal age; this, as in the present study, is generally the case (Gray 1976; Bongaarts and Potter 1983). There are, however, some indirect suggestions that in very poorly nourished populations ages at menarche and menopause may actually be negatively correlated (Gray 1979), generating a further advantage in terms of reproductive lifespan to early maturers; in the Kipsigis, despite chronic food shortages on a seasonal basis (Borgerhoff Mulder 1987a), there was no evidence of such an effect.

In short, early maturing Kipsigis women neither continue to reproduce to an older absolute age than late maturing women, nor are they more fertile at older ages and higher parities; rather, they appear to derive their reproductive advantage, at least in part, from starting to reproduce early. Note however, that even after controlling for length of reproductive lifespan, early maturing women produce more live-births than do late maturing women. Why should this be?

b) Attitudinal factors. Ryder $(1969,1976)$ suggests that the low reproductive performance of women who start reproducing late may result from a difference in attitudes compared to those of women who start early. Specifically, an initial postponement of reproduction gives a woman the opportunity to revise her fertility preferences downwards, perhaps because the experiences of education and employment foster sources of satisfaction other than motherhood. According to this argument, smaller family sizes are deliberately chosen as a consequence of socioeconomic experiences that delay reproduction in some women (see also Aghajanian 1981; Bumpass et al. 1978).

Such an interpretation is questionable in the Kipsigis case. None of the women in any of the cohorts were employed, and the association between age at clitoridectomy and reproductive success was independent of educational differences (Borgerhoff Mulder 1987c). Furthermore, none of the women used modern birth control techniques whereby they might effectively limit family size, even if they so wanted. The attitudinal factors proposed by Ryder and others are therefore unlikely to account for the reproductive advantage of early maturing Kipsigis women.

Udry and Cliquet (1982; see also Udry 1979) propose a more sophisticated version of this argument, suggesting that socially mediated pressures may interact with differences in maturational timing. First, early maturing women (with developed secondary sexual characteristics) will become attractive to men at an earlier absolute age, an "attractiveness" that may precipitate early marriage and/or pregnancy. Second, they suggest that early maturing girls may receive more parental and peergroup encouragement to marry and reproduce than do late maturing girls.

Such kinds of subtle pressures may contribute to the high reproductive success of early maturing Kipsigis women, but are difficult to measure. Because men pay more for girls who reach menarche early, there is a possibility that such highly-priced women feel more obligated to produce large families than those who are lower priced; the mechanisms whereby such an effect could occur are entirely unknown. Yet, in casual conversation with me, many Kipsigis women said that their first and foremost role in life was to be a good mother, specifically stating that they felt they must justify the bridewealth paid for them (see Hakansson 1985 for similar sentiments among neighboring Gusii).

In sum, attitudinal factors may contribute to the high reproductive success of early maturing Kipsigis women; subtle parental and peer pressures may interact with the particular rates of physiological maturation experienced by different women. 
c) Physiological factors. Early maturity could be an index of other physiological (particularly nutritional) differences among women, and these differences, rather than age at menarche per se, may be responsible for subsequent reproductive differences (cf. Udry and Cliquet 1982).

This argument is controversial. Frisch and her colleagues proposed that a critical threshold of fat (Frisch and McArthur 1974; Frisch 1975) determines not only menarcheal age but also regular menstrual cycling, and is therefore an important factor influencing subsequent fertility. Indirect support from a number of sources initially lent appeal to the so-called "critical fat" hypothesis: secular declines in menarcheal age in European populations over the last 80 years, associated with increased stature and improved diet (Tanner 1981); secondary amenorrhea in times of starvation (Menken et al. 1981; Bongaarts 1980); and delayed menarcheal age in nutritionally and socially deprived groups, as compared both between (Bongaarts et al. 1984) and within contemporary populations (Burrel et al. 1961; Frisch 1972; Jones et al. 1973). The present finding that early maturing Kipsigis women come from richer parental homes, previously shown to enjoy a greater availability of food (Borgerhoff Mulder 1987a), is consistent with these observations.

Despite strong theoretical, methodological and empirical criticisms of the concept of a threshold and the fertility-inhibiting mechanisms involved (Ellison 1981; Scott and Johnston 1982, 1985; Garn et al. 1983), there is considerable evidence that fatness, weight and nutritional status are positively associated with early menarche (Garn and Haskell 1959; Garn et al. 1986) and other aspects of successful reproductive performance: poor nutritional status contributes to longer periods of lactational ammenorhea (Delgado et al. 1978; Jelliffe and Jelliffe 1978; Prema et al. 1981; Lunn et al. $1980,1984)$ and lowered fecundability (reviewed in Gray 1983); low maternal weight is associated with increased pregnancy risk, slow fetal growth and low birth weights (Lechtig and Klein 1981; Bongaarts and Potter 1983; Garn and LaVelle 1983; Gray 1983). It is important to note that the mechanisms whereby fatness, weight and nutritional status affect maturational timing and subsequent reproductive performance are not clearly determined. Furthermore, such effects are likely to result from interactions with behavioral factors (Wray 1977), infectious disease (Gray 1983) and perhaps also endocrinological profiles (Apter and Vikho 1983). The weight of current evidence nevertheless suggests that it is fair to conclude that physiological effects of nutritional differences, dating perhaps from early in life, may underly the correlations between parental wealth, age at menarche and subsequent reproductive success in Kipsigis women.

\section{Bridewealth, menarche and the bride's parents' wealth}

Kipsigis men gain potential reproductive benefits from marrying young maturing women. There is, however, a strange anomaly in these findings: the demographic results from cohort II show that the wealth of a bride's parents is in fact an even better predictor of her future reproductive success than is her age at menarche, even though menarcheal age and parental wealth are correlated. If men vary marriage payments with respect to their prospective bride's future reproductive success, higher bridewealth should be paid for brides from rich families. There was no evidence of this, raising the question: Why is the eventual outcome of bridewealth negotiations influenced by the bride's age at menarche rather than her parents' wealth?

Anthroplogists traditionally answer such questions by referring to culturally specific factors (Parkin 1980), that is factors that are irreduceable to the econmics or ecology of the society. It may, however, be instructive to examine whether an understanding of recent changes in the economic basis of Kipsigis society can throw light on this anomaly.

Before the development of individual land holdings in the late 1920 s, wealth differentiation among Kipsigis men was based entirely on livestock. Some families were markedly richer in cattle, goats and sheep than were others, enjoying a higher standard of living as a result (Peristiany 1939), but the stability of such wealth differences over time is questionable. Most importantly, livestock (particularly cattle) were subject to raids from other ethnic groups and to mortality from both epidemic and enzootic disease (Peristiany 1939; Orchardson 1961; Mwanzi 1977; Toweett 1979). Prior to the formal suppression of intertribal raids (Manners 1967) and the introduction of preventative veterinary medicine during the colonial era, each family (rich or poor) ran considerable risk of losing a large proportion of their stock. The customary risk-averting practice of loaning livestock to men living in different districts (kimanagan, Peristiany $1939: 150$ ) attests to the very real threat of such an event.

The unstable traditional pattern of wealth differentiation differs markedly from that observed during my period of study. Individually-owned plots now form the basis of a far more entrenched 
system of wealth differentiation than did livestock in the past (see Haugerud 1983 for other East African examples). Whereas nowadays the current wealth status of a man is a good indicator of his wealth 20 to 30 years ago (Borgerhoff Mulder $1987 \mathrm{~b}$ ), this is unlikely to have been true in the traditional system. Specifically, in a land-based stratification system, a bride's parents' current wealth status can be used as a reliable indicator of the wealth of the household in which she grew up; this would not have been the case in the livestock-based stratification system of the past.

Given these changes in the stratification system, we can speculate that in the past a good "rule of thumb" for assessing a bride's reproductive value may have been her age at menarche, if menarcheal age reflects nutritional differences during development and predicts subsequent reproductive performance. In this sense, then, menarcheal age was an "honest signal" (Davies and Halliday 1978; Clutton-Brock and Albon 1979) of future reproductive performance. More recently, however, with the development of individual land holdings a bride's parents' wealth is a better predictor of her subsequent reproductive success than age at menarche. Men appear to have not yet adapted their "rule of thumb" to these new environmental conditions, at least in so far as no differences over time were shown in the effects of bride's parents' wealth on bridewealth.

It is unlikely that all aspects of human cultural variability are amenable to analyses of this sort. Nevertheless these findings suggest that determining the adaptive consequences of at least some culturally transmitted human behavior patterns (Richerson and Boyd 1987) provides a conceptual starting point from which to examine both intercultural variability in the determinants of bridewealth payments and, more generally, the reasons why some cultures are notable for payments from the groom to the bride whereas others are noted for payments in the opposite direction (Borgerhoff Mulder 1988a).

Acknowledgements. Steve Albon, Tim Caro, Tim CluttonBrock, Roberto Frisancho, Stanley Garn, Ian Gordon, John Hartung, Kim Hill, Joan Silk and 2 referees all made helpful comments on earlier drafts. I am very grateful to the people of Abosi, Kamerumeru and Tabarit for their friendly cooperation throughout this study, to The Office of the President for permission to conduct research in Kenya, and to Tim CluttonBrock and members of the Large Animal Research Group of the Department of Zoology, University of Cambridge, for hospitality and facilities during analysis. The study was funded by the National Geographic Society and a Northwestern University Graduate School Dissertation Fellowship.

\section{References}

Aghajanian A (1981) Age at first birth and completed family size in western Malaysia. J Biosocial Sci 13:197-201

Apter D, Vikho R (1983) Early menarche, a risk factor for breast cancer. J Clin Endocrinol Metab 57:82-86

Bongaarts J (1980) Does malunutrition affect fecundity? A summary of the evidence. Science 208:565-569

Bongaarts J, Potter RG (1983) Fertility, biology and behavior: An analysis of the proximate determinants. Academic Press, New York

Bongaarts J, Frank O, Lesthaeghe R (1984) The proximate determinants of fertility in sub-Saharan Africa. Popul Demo Rev 10:511-537

Borgerhoff Mulder M (1985) Polygyny threshold: a Kipsigis case study. Nat Geo Res Rep 21:33-39

Borgerhoff Mulder M (1987a) Resources and reproductive success in women, with an example from the Kipsigis. J Zool 213:489-505

Borgerhoff Mulder M (1987b) On cultural and reproductive success: Kipsigis evidence. Am Anthropol 89:617-634

Borgerhoff Mulder M (1987c) Marriage and reproduction in the Kipsigis of Kenya. Phd dissertation, Northwestern University

Borgerhoff Mulder M (1987d) Adaptation in evolutionary biological anthropology. Man 22:24-41

Borgerhoff Mulder M (1988a) Kipsigis bridewealth payments. In: Betzig L, Borgerhoff Mulder M, Turke P (eds) Human reproductive behaviour. Cambridge University Press, Cambridge, pp 65-82

Borgerhoff Mulder M (1988b) Reproductive success in three Kipsigis cohorts. In: Clutton-Brock TH (ed) Reproductive success. Chicago University Press, Chicago, pp 419-435

Borgerhoff Mulder M (1989a) Reproductive consequences of sex-biased inheritance for the Kipsigis. In: Standen V, Foley RA (eds) Comparative socioecology. Blackwell, Oxford (in press)

Borgerhoff Mulder M (1989b) Menarche, menopause and reproduction in the Kipsigis of Kenya. J Biosocial Sci (in press)

Bumpass L, Rindfuss R, Janosik R (1978) Age and marital status at first birth and the pace of subsequent fertility. Demography 15:75-86

Burrell RJW, Healey MJR, Tanner JM (1961) Age at menarche in South African Bantu school girls living in the Transkei Reserve. Hum Biol 33:250-261

Caro TM, Borgerhoff Mulder M (1987) The problem of adaptation in the study of human behavior. Ethol Sociobiol $8: 61-72$

Clutton-Brock TH, Albon SD (1979) The roaring of red deer and the evolution of honest advertisement. Behaviour 69:145-170

Comaroff JL (ed) (1980) The meaning of marriage payments. Academic Press, New York

Critescu M (1975) Differential fertility depending on the age of puberty. J Hum Evol 4:521-524

Cutler WB, Garcia CR, Krieger AM (1979) Infertility and age at first coitus: a possible relationship. J Biosocial Sci $11: 425-432$

Davies NB, Halliday TR (1978) Deep croaks and fighting assessment in toads Bufo bufo. Nature 274:683-685

Delgado H, Lechtig A, Martorell F, Brineman E (1978) Nutrition, lactation and postpartum amenorrhea. Am J Clin Nutr $31: 322-327$

Ellison PT (1981) Prediction of age at menarche for annual height increments. Am J Phys Anthropol 56:71-75 
Epstein E, Guttman R (1984) Mate selection in man: Evidence, theory and outcome. Soc Biol $31: 243-278$

Fisher RA (1958) The genetical theory of natural selection. Oxford University Press, Oxford

Frisch RE (1972) Weight at menarche: similarity for wellnourished and undernourished girls at differing ages, and evidence for historical constancy. Pediatrics 50:445-450

Frisch RE (1975) Critical weights, a critical body composition, menarche and the maintenance of menstrual cycles. In: Watts ES, Johnson FE, Lasker GW (eds) Biosocial interelations in population adaptation. Mouton, The Hague, pp 319-351

Frisch RE, McArthur JW (1974) Menstrual cycles: fatness as a determinant of minimum weight for height necessary for the maintenance and onset. Science 185:949-951

Garn SM, Haskell JA (1959) Fat and growth during childhood. Science 130:1711-1712

Garn SM, LaVelle M (1983) Reproductive histories of low weight girls and women. Am J Clin Nutr 37:862-866

Garn SM, LaVelle M, Pilkington JJ (1983) Fatness comparisons of premenarcheal and postmenarcheal girls at the same age. J Pediatr 103:328-331

Garn SM, LaVelle M, Rosenberg KR, Hawthorne VM (1986) Maturational timing as a factor in female fatness and obesity. Am J Clin Nutr 43:879-883

Gray RH (1976) The menopause - epidemiological and demographic considerations. In: Beard RJ (ed) The menopause: A guide to current research and practice. University Park Press, Baltimore, pp 26-40

Gray RH (1979) Biological and social interactions in the determination of late fertility. J Biosocial Sci (Suppl) 6:97-115

Gray RH (1983) The impact of health and nutrition on natural fertility. In: Bulatao RA, Lee RD (eds) Determinants of fertility in developing countries, vol 1. Supply and demand for children. Academic Press, New York, pp 139-162

Gubhaju B (1983) Fertility differentials in Nepal. J Biosocial Sci $15: 325-331$

Hakansson T (1985) Who do Gusii women get maried? A study of cultural constraints and women's strategies in a rural community in Kenya. Folk 27:89-114

Haugerud A (1983) The consequences of land tenure reform among smallholders in the Kenya Highlands. Rural Africana 15-16:65-89

Jelliffe DB, Jelliffe EFP (1978) Human milk in the modern world: Psychosocial, nutritional, and economic significance. Oxford University Press, Oxford

Jones B, Leeton J, McLeod I, Wood C (1973) Factors influencing the age of menarche in a lower socioeconomic group in Melbourne. Med $\mathrm{J}$ Aust 2:533-535

Lechtig A, Klein RE (1981) Pre-natal nutrition and birth weight: Is there a causal association? In: Dobbing J (ed) Maternal nutrition in pregnancy - eating for two? Academic Press, New York, pp 131-174

Lunn PG, Prentice AM, Austin S, Whitehead RG (1980) Influence of maternal diet on plasma-prolactin levels during lactation. Lancet I:623-625

Lunn PG, Austin S, Prentice AM (1984) The effects of improved nutrition on plasma prolactin concentrations and postpartum infertility in lactating Gambian women. Am J Clin Nutr 39:227-235

Mair L (1969) African marriage and social change. Frank Cass, London

Manners RA (1967) The Kipsigis of Kenya: culture change in a "model" East African Tribe. In: Steward $\mathbf{J}$ (ed) Contemporary change in traditional societies, Vol I. Introduc- tion and African tribes. University of Illinois Press, Urbana, pp 207-359

Mascie-Taylor CGN (1988) Assortative mating for psychometric characters. In: Mascie-Taylor CGN, Boyce AJ (eds) Mating patterns. Cambridge University Press, Cambridge (in press)

Menken J, Trussel J, Watkins S (1981) The nutrition-fertility link: An evaluation of the evidence. J Interdiscip Hist $11: 425-441$

Mwanzi HA (1977) A history of the Kipsigis. East African Literature Bureau, Nairobi

Orchardson IQ (1961) The Kipsigis. Kenya Literature Bureau, Nairobi

Parkin D (1980) Kind bridewealth and hard cash. In: Comaroff JL (ed) The meaning of marriage payments. Academic Press, New York, pp 197-220

Peristiany JG (1939) The social institutions of the Kipsigis. Routledge and Kegan Paul, London

Pilgrim J (1961) Social and economic consequences of land enclosure in the Kipsigis Reserve. East African Institute of Social Research, Kampala

Prema KA, Nadamuni A, Neelakumari S, Ramalakshmi BA (1981) Nutrition-fertility interaction in lactating women of low income groups. Br J Nutr 45:461-467

Richerson PJ, Boyd R (1987) Simple models of complex phenomena: The case of cultural evolution. In: Dupré $J$ (ed) The latest on the best. MIT Press, Cambridge, pp 2752

Ryder NB (1969) Relationship among intended, expected, desired and ideal family size: United States, 1965. Center for Population Research, Princeton

Ryder NB (1976) Some sociological suggestions concerning the reduction of fertility in developing countries. Paper No. 37, East-West Population Institute, Honolulu

Ryder NB, Westoff CF (1971) Reproduction in the United States. Princeton University Press, Princeton

Saltman M (1977) The Kipsigis: A case study in changing customary law. Shehkman Publishing Company, Massachusetts

Sandler DP, Wilcox AJ, Horney LF (1984) Age at menarche and subsequent reproductive events. Am J Epidemiol 19:765-774

Scott EC, Johnston FE (1982) Critical fat, menarche, and the maintenance of menstrual cycles: A critical review. J Adolescent Health Care 2:249-260

Scott EC, Johnston FE (1985) Science, nutrition, fat, and policy: Tests of the critical-fat hypothesis. Curr Anthropol 26:463-473

Tanner JM (1981) A history of the study of human growth. Cambridge University Press, Cambridge

Thiessen D, Gregg B (1980) Human assortative mating and genetic equilibrium: An evolutionary perspective. Ethol Sociobiol $1: 111-140$

Toweett T (1979) The oral traditional history of the Kipsigis. Kenya Literature Bureau, Nairobi

Udry JR (1979) Age at menarche, at first intercourse, and at first pregnancy. J Biosocial Sci 11:433-441

Udry JR, Cliquet RL (1982) Cross-cultural examination of relationships between ages at menarche, marriage and first birth. Demography 19:53-63

Williams GC (1975) Sex and evolution. Princeton University Press, Princeton

Wray MD (1977) Maternal nutrition, breast feeding and infant survival. In: Mosley WH (ed) Nutrition and human reproduction. Plenum Press, New York, pp 197-230 